\title{
Interferon as a treatment for uveitis associated with multiple sclerosis
}

\author{
M D Becker, A Heiligenhaus, T Hudde, B Storch-Hagenlocher, B Wildemann, T Barisani- \\ Asenbauer, C Thimm, N Stübiger, M Trieschmann, C Fiehn
}

Br J Ophthalmol 2005;89:1254-1257. doi: 10.1136/bjo.2004.061119

\begin{abstract}
Aim: In addition to optic neuritis (ON), multiple sclerosis (MS) may also involve the eye with a typically bilateral intermediate uveitis. The aim of this pilot study was to evaluate the efficacy of type I interferons (IFN) for the treatment of MS associated uveitis.

Methods: In this non-randomised, retrospective observational case series 13 patients (eight female, five male) with proved MS and associated uveitis from five uveitis centres who were treated with interferon $\beta$ la were included. Visual acuity (VA), cell count in the aqueous humour and vitreous, as well as the presence of cystoid macula oedema (CMO) were observed.

Results: All except one patient had a bilateral form of intermediate uveitis (total of 24 eyes). Seven patients had documented CMO before IFN treatment ( $n=13$ eyes). Median duration of treatment was 24.6 months (range 7.9-78.7). VA improved in 17 eyes (comparing VA before therapy and at last follow up); while 10 eyes (36\%) improved $\geqslant 3$ Snellen lines. Aqueous cell count improved by 1.2 (SD $1.1)$ grades in all eyes. Vitreous cell count improved by 1.7 (1.4) in all eyes. Only two patients still had minimal CMO on last follow up angiographically. CMO resolved after or during IFN treatment in nine eyes.

Conclusions: IFN has been shown to have beneficial effects in patients with MS and/or ON. As shown in the models of experimental allergic encephalomyelitis (EAE) and uveitis, the neurological and ophthalmological manifestations seem to share similar pathogenic mechanisms. Treatment of MS associated uveitis with IFN appears to have beneficial effects on VA, intraocular inflammation activity, and the presence of CMO.
\end{abstract}

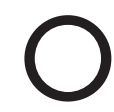

ptic neuritis is the most common ocular manifestation of multiple sclerosis (MS), occurring in an estimated $30 \%$ of patients ${ }^{1}$; however, intraocular inflammation also occurs. Originally described by Rucker ${ }^{2}$ the occurrence of this association varies widely, ranging from $0.4 \%$ to $26.9 \%$ in patients with $\mathrm{MS}^{3-5}$ and from $0.8 \%$ to $14 \%$ in patients with uveitis. ${ }^{6-8}$ The most common type of uveitis is intermediate uveitis (according to Bloch-Michel and Nussenblatt ${ }^{9}$ ) with characteristic changes. Patients may also present with granulomatous changes in the anterior segment..$^{50-12}$ In these patients secondary changes like the formation of cystoid macula oedema (CMO), or occlusive vasculitis with vasoproliferations often develop-changes that have a profound effect on visual prognosis. If these secondary changes occur, the disease is often difficult to manage, requires high doses of corticosteroids ${ }^{13}$ or laser treatment, and often remains refractory to these standard therapies. Treatment with interferon $\beta$ (IFN- $\beta$ ) is established for the treatment of MS. Therefore, the aim of this pilot study was to evaluate the efficacy of IFN- $\beta$ for MS associated uveitis in a multicentre, retrospective, uncontrolled study.

\section{PATIENTS AND METHODS}

We included 13 patients (eight females, five males) with proved MS and associated uveitis from five uveitis centres. As the data were analysed retrospectively (chart review) and the treatment with IFN was started because of individual treatment decisions for every patient, no informed consent, institutional, or ethics committee approval were required for this study. Since this is a retrospective study, the five centres did not coordinate the type of drug and treatment regimen, study design, inclusion/exclusion criteria, or follow up intervals for the individual patients in advance. Patients were recruited independently based on the experience of the individual centre after failure of systemic corticosteroids and/ or systemic immunosuppressive treatment. In cooperation with consulting neurologists the diagnosis of MS was approved in all patients after neurological examination and magnetic resonance imaging (MRI) according to the guidelines described by Poser et al. ${ }^{14}$

Median age of all patients at the time of data analysis (March 2004) was 48 years (range 34-58 years). All except one patient had bilateral uveitis (total of 25 eyes). In seven patients MS started a median of 8.2 years (range 2.8-24.2) before uveitis, in six patients uveitis was diagnosed a median of 5.5 years $(0.3-20.6)$ before MS. Seven of 13 patients had had ON in at least one eye during the previous course of their disease. In all patients ON happened before the onset of uveitis. Aqueous humour and vitreous cell count were graded as rare cells, $1+, 2+, 3+$, and $4+\left(\right.$ according to BenEzra et $\left.a l^{15}\right)$. A change in this grading scale is given as +1 when cell count increases by one step, and one when cell count improved $(+/-0.5$ was used in the range of no cells, rare cells, $1+$ cells $)$. Change in VA is given as change of line in Snellen charts, respectively.

All patients received systemic corticosteroids for the treatment of uveitis according to the experience and choice of the individual centre or the urgency of uveitic complications either with initial doses on a $1 \mathrm{mg} / \mathrm{kg}$ bodyweight basis or on a mega dose methylprednisolone scheme. Systemic corticosteroids did not (or only in doses above $10 \mathrm{mg} /$ day) improve disease activity sufficiently on a clinical basis (according to the documentation of the individual centres). Corticosteroid sparing agents were used before initiation of IFN therapy in two patients (one patient methotrexate, one azathioprine). However, this therapy was considered to be without success in those centres because of recurrences of inflammation and further deterioration in VA. After a median

Abbreviations: $C M O$, cystoid macula oedema; $E A E$, experimental allergic encephalomyelitis; IFN, interferon; MRI, magnetic resonance imaging; MS, multiple sclerosis; ON, optic neuritis; VA, visual acuity 


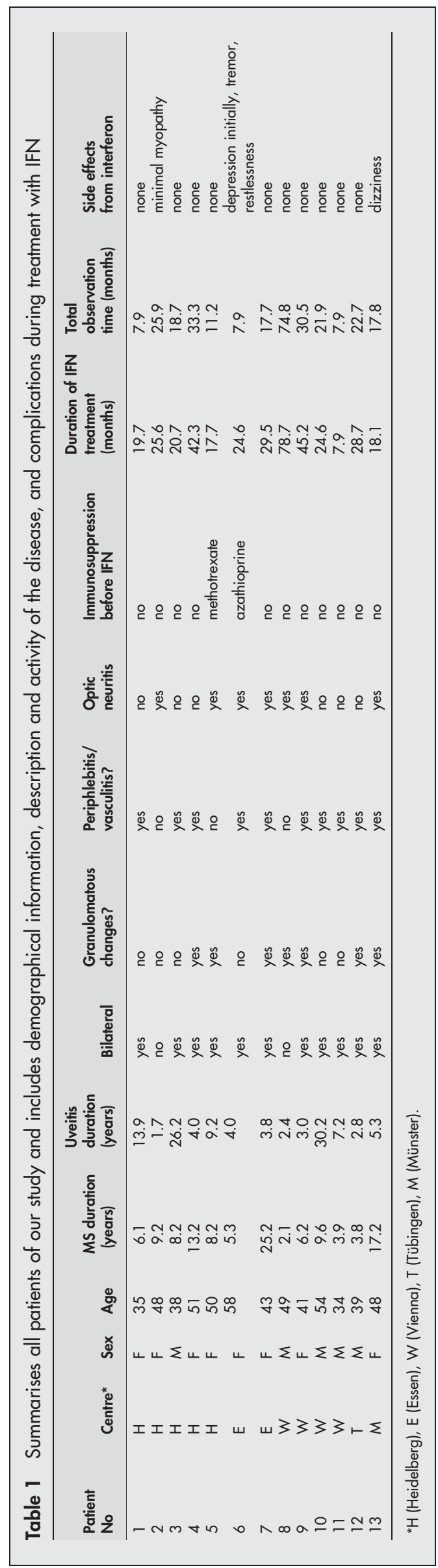

of 2.3 years (range 0.3-27) after the onset of uveitis, patients were put on IFN therapy. Median duration of treatment was 24.6 months (range 7.9-78.7). The choice of drug was based on the personal experience and preference of each individual centre. According to the clinical response to IFN therapy patients who were treated with IFN- $\beta$ la either received $22 \mu \mathrm{g}$ or $44 \mu \mathrm{g}$ (Rebif, Serono Inc, $\mathrm{n}=10$ ) three times per week subcutaneously or $30 \mu \mathrm{g}$ once a week intramuscularly (Avonex, Biogen Inc, patients 8, 10, and 11).

Primary outcome measures were defined as improvement in VA and reduction of cell count in the aqueous humour and vitreous. Secondary outcome measures were the presence of CMO. No statistical analysis was performed because of the small sample size.

The characteristics of all patients including treatment strategy and change of inflammatory activity and secondary complications during IFN treatment are summarised in table 1 .

\section{RESULTS}

During treatment with IFN, 17 eyes $(71 \%)$ improved their VA, five did not change $(21 \%)$, and two eyes deteriorated $(8 \%)$ because of development of cataract. Figures 1 and 2 demonstrate the change of VA between initial and last visit.

Aqueous cell count improved by $1.2(1.1)$ grades in all eyes (64\% improved, no change in $21 \%$ ). Vitreous cell count improved by 1.7 ( 1.4 ) in all eyes (71\% improved, $11 \%$ did not change, and $4 \%$ deteriorated).

At their last visit before IFN therapy was initiated seven patients had CMO (13 eyes). At the last follow up during or after therapy (median total observation time 18.7 months, range 7.9-74.8 months), in two patients CMO was still detectable angiographically but reduced before IFN therapy at their last follow up while CMO resolved after or during IFN treatment in nine patients $(82 \%)$.

At the last visit nine patients were not on systemic corticosteroids (69\%). A reduction in the dose of prednisone to $10 \mathrm{mg} /$ day or less (or its equivalent for other corticosteroids) while maintaining inactive uveitis during IFN therapy was considered a successful corticosteroid sparing in our study. The corticosteroid sparing effect of IFN treatment has been documented in almost all cases. At final follow up examination only one of 13 patients had to use prednisone at a dose above $10 \mathrm{mg} /$ day at her last follow up visit because of a recent flare up (patient $1,50 \mathrm{mg} /$ day).

Three of 13 patients (23\%) had side effects as documented in table 1. However, in no patients did IFN therapy have to be discontinued because of intolerable side effects.

Details on the course of VA and intraocular inflammatory activity as well as of the side effects and the surgical

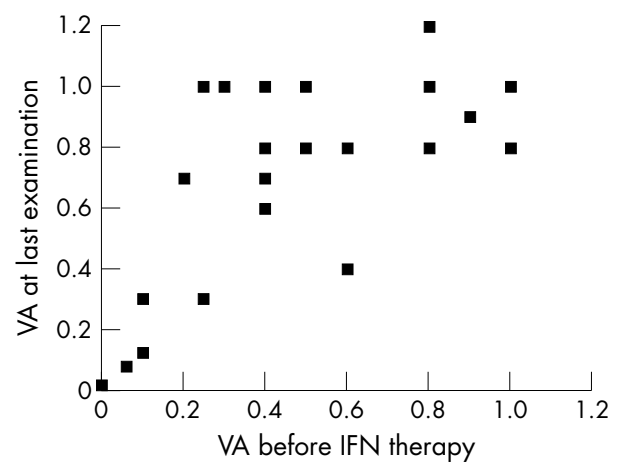

Figure 1 Comparison of the VA before treatment with IFN and at last follow up examination. Two eyes had reduced vision compared to initial examination because of development of cataract. 


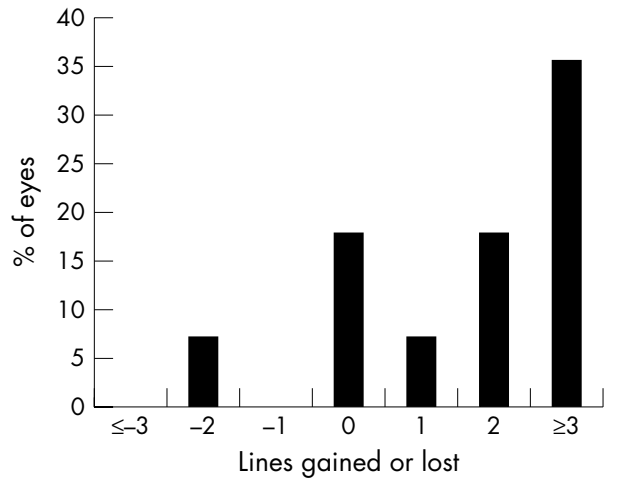

Figure 2 This graph shows the percentage of eyes that gained or lost Snellen lines. In two eyes VA deteriorated because of the development of cataracts.

procedures that were performed during the treatment period with IFN are summarised in table 2.

\section{DISCUSSION}

This multicentre, retrospective, observational case series with a small number of patients suggests that treatment of MS associated uveitis with IFN- $\beta$ may improve intraocular inflammatory activity as well as the presence of CMO, and hence improve VA.

IFN has been shown to have beneficial effects in patients with $\mathrm{MS}^{16}{ }^{17}$ and/or ON. ${ }^{18}$ Jacobs et al showed that initiating treatment with IFN- $\beta$ la at the time of a first demyelinating event, like optic neuritis, is beneficial for patients with brain lesions on MRI that indicate a high risk of clinically definite multiple sclerosis. ${ }^{19}$

In the model of experimental allergic encephalomyelitis (EAE), a classic model for MS, animals also develop a temporary, mild, bilateral uveitis. ${ }^{20} 21$ This suggests shared antigenic determinants between neurological and ophthalmological manifestations with similar pathomechanisms. ${ }^{21}$ Treatment with IFN- $\beta$ reduced ocular inflammation in this model. $^{22}$

This beneficial effect may be useful, especially in patients with partial resistance to systemic corticosteroids or immunosuppressive drugs. Side effects from IFN treatment did not appear in most of the patients, or were tolerable in most patients. The effects of IFN on posterior segment findings were mostly related to a reduced vascular leakage and hence the improvement of macular oedema. The pronounced antioedematous effect of type I IFNs in this small group of patients should be further evaluated since chronic inflammatory CMO is a known problem with conventional treatment.

Whether glatiramer acetate (copolymer-1, Copaxone) could be helpful in the treatment of uveitis would be interesting to know. Its experimental effect has been shown in animal studies. ${ }^{23}$ Recently, a systematic Cochrane review of all randomised controlled trials of glatiramer acetate found little support for use of this drug in patients with MS. ${ }^{24}{ }^{25}$ To the best of our knowledge there is no literature about the effect of glatiramer acetate in uveitis.

One of the limitations of our study is that the possibility of spontaneous improvement is not recognised. Since MS can be of the relapsing/remitting type and since uveitis will sometimes follow the pattern of the underlying MS, patients might have improved without regard to treatment. Owing to incomplete documentation in the different centres, the type of MS was not specified and therefore cannot be correlated with the ocular response to treatment. Because of the lack of a study protocol, all results are given as of "final visit" - the actual pace of the clinical response cannot be deduced from our data.

These promising results are encouraging us to further evaluate the effect of IFN on MS associated uveitis. We think especially that patients with inflammatory CMO due to intermediate uveitis and with MS could benefit from IFN therapy. An investigator initiated trial with controlled studies is in preparation. This study could show if the preliminary observations herein can be confirmed and if the long term prognosis concerning VA and neurological MS may be improved by this treatment, whose key concept is immunomodulation rather than immunosuppression.

\section{Authors' affiliations}

M D Becker, C Fiehn, Interdisciplinary Uveitis Center, University of Heidelberg, Germany

M D Becker, Department of Ophthalmology, University of Heidelberg,

Germany

A Heiligenhaus, $M$ Trieschmann, Department of Ophthalmology at $\mathrm{St}$ Franziskus Hospital, Münster, Germany

T Hudde, Department of Ophthalmology, University of Essen, Germany

B Storch-Hagenlocher, B Wildemann, Department of Neurology,

University of Heidelberg, Germany

T Barisani-Asenbaver, Department of Ophthalmology, University of Vienna, Austria

C Thimm, N Stübiger, Department of Ophthalmology, University of Tübingen, Germany

C Fiehn, Department of Internal Medicine, University of Heidelberg, Germany and Centre of Rheumatic Diseases, Baden-Baden, Germany

Table 2 Change in VA, cell count, and surgical procedures that were performed during the treatment period with IFN

\begin{tabular}{|c|c|c|c|c|c|c|c|c|c|c|c|}
\hline No & $\begin{array}{l}\text { CMO } \\
\text { initially }\end{array}$ & $\begin{array}{l}\text { CMO at } \\
\text { last follow } \\
\text { up? }\end{array}$ & $\begin{array}{l}\text { Proliferative } \\
\text { changes } \\
\text { initially }\end{array}$ & $\begin{array}{l}\text { Proliferative } \\
\text { change at last } \\
\text { follow up? }\end{array}$ & $\begin{array}{l}\text { VA } \\
\text { change } \\
\text { RE }\end{array}$ & $\begin{array}{l}\text { VA } \\
\text { change } \\
\text { LE }\end{array}$ & $\begin{array}{l}\text { AC cell } \\
\text { grading } \\
\text { change RE }\end{array}$ & $\begin{array}{l}\text { AC cell } \\
\text { grading } \\
\text { change LE }\end{array}$ & $\begin{array}{l}\text { Vitreous cell } \\
\text { grading } \\
\text { change RE }\end{array}$ & $\begin{array}{l}\text { Vitreous cell } \\
\text { grading } \\
\text { change LE }\end{array}$ & $\begin{array}{l}\text { Surgical procedures } \\
\text { during IFN treatment }\end{array}$ \\
\hline 1 & no & no & no & no & 3 & 0 & -1 & -1 & -2 & -2 & none \\
\hline 2 & yes & no & no & no & 6 & 0 & -3 & 0 & -4 & 0 & none \\
\hline 3 & & & no & no & -2 & 0 & -1 & -1 & -1 & 0 & none \\
\hline 4 & yes & yes & yes & no & 4 & 4 & 0 & 0 & -2 & -3 & none \\
\hline 5 & & & no & no & 2 & 1 & -1 & -1 & -1 & -1 & cataract extraction $O D$ \\
\hline 6 & yes & yes & no & no & 2 & 1 & 0 & 0 & -0.5 & -0.5 & $\begin{array}{l}\text { argon laser coagulation, } \\
\text { vitrectomy + ILM-peeling }\end{array}$ \\
\hline 7 & no & no & no & no & 0 & 0 & -0.5 & -0.5 & 0 & 0 & none \\
\hline 8 & no & no & no & no & 2 & 0 & -2 & 0 & -2 & 0 & none \\
\hline 9 & yes & no & no & no & 0 & 3 & -2 & -4 & 1 & -1 & none \\
\hline 10 & yes & no & no & no & 4 & 3 & -2 & -2 & -4 & -4 & none \\
\hline 11 & yes & no & yes & no & 4 & 4 & 0 & 0 & -2 & -2 & argon laser coagulation \\
\hline 12 & no & no & yes & no & -2 & 2 & -3 & -3 & -1 & -3 & none \\
\hline 13 & yes & no & yes & no & 5 & 2 & -1 & -2 & -2 & -3 & none \\
\hline
\end{tabular}


Correspondence to: Matthias D Becker, MD, PhD, FEBO, Interdisciplinary Uveitis Center, University of Heidelberg, Im Neuenheimer Feld 350, 69120 Heidelberg, Germany; matthias. becker@uveitiscenter.de

Accepted for publication 1 May 2005

\section{REFERENCES}

1 Optic Neuritis Study Group. The 5-year risk of MS after optic neuritis. Experience of the optic neuritis treatment trial. Neurology 1997;49:1404-13.

2 Rucker CW. Sheathing of the retinal veins in multiple sclerosis. Review of pertinent literature. Mayo Clin Proc 1972;47:335-40.

3 Breger BC, Leopold $\mathrm{IH}$. The incidence of uveitis in multiple sclerosis. Am J Ophthalmol 1966;62:540-5.

4 Porter R. Uveitis in association with multiple sclerosis. Br J Ophthalmol 1972;56:478-81.

5 Bamford CR, Ganley JP, Sibley WA, et al. Uveitis, perivenous sheathing and multiple sclerosis. Neurology 1978;28:119-24.

6 Malinowski SM, Pulido JS, Folk JC. Long-term visual outcome and complications associated with pars planitis. Ophthalmology 1993;100:818-24; discussion 825.

7 Rothova A, Buitenhuis HJ, Meenken C, et al. Uveitis and systemic disease. $\mathrm{Br} J$ Ophthalmol 1992;76:137-41.

8 James DG, Friedmann Al, Graham E. Uveitis. A series of 368 patients. Trans Ophthalmol Soc UK 1976;96:108-12.

9 Bloch-Michel E, Nussenblatt RB. International Uveitis Study Group recommendations for the evaluation of intraocular inflammatory disease. Am J Ophthalmol 1987; 103:234-5.

10 Biousse V, Trichet C, Bloch-Michel E, et al. Multiple sclerosis associated with uveitis in two large clinic-based series. Neurology 1999;52:179-81.

11 Acar MA, Birch MK, Abbott R, et al. Chronic granulomatous anterior uveitis associated with multiple sclerosis. Graefes Arch Clin Exp Ophthalmol 1993;231:166-8.
12 Towler HM, Lightman S. Symptomatic intraocular inflammation in multiple sclerosis. Clin Experiment Ophthalmol 2000;28:97-102.

13 Wakefield D, Jennings A, McCluskey PJ. Intravenous pulse methylprednisolone in the treatment of uveitis associated with multiple sclerosis. Clin Experiment Ophthalmol 2000;28:103-6.

14 Poser CM, Paty DW, Scheinberg L, et al. New diagnostic criteria for multiple sclerosis: guidelines for research protocols. Ann Neurol 1983;13:227-31.

15 BenEzra D, Ohno S, Secchi A, et al. Anterior segment intraocular inflammation guidelines. London: Martin Dunitz, 2000.

16 PRISMS-4. Long-term efficacy of interferon-beta-la in relapsing MS. Neurology 2001;56:1628-36.

17 PRISMS. (Prevention of Relapses and Disability by Interferon beta-1a Subcutaneously in Multiple Sclerosis) Study Group. Randomised double-blind placebo-controlled study of interferon beta- $1 \mathrm{a}$ in relapsing/remitting multiple sclerosis. Lancet 1998;352:1498-504.

18 Group CS. Interferon beta-l a for optic neuritis patients at high risk for multiple sclerosis. Am J Ophthalmol 2001;132:463-71.

19 Jacobs LD, Beck RW, Simon JH, et al. Intramuscular interferon beta- la therapy initiated during a first demyelinating event in multiple sclerosis. CHAMPS Study Group. N Engl J Med 2000;343:898-904.

20 Constantinescu CS, Lavi E. Anterior uveitis in murine relapsing experimental autoimmune encephalomyelitis (EAE), a mouse model of multiple sclerosis (MS). Curr Eye Res 2000;20:71-6.

21 Adamus G, Amundson D, Vainiene M, et al. Myelin basic protein specific Thelper cells induce experimental anterior uveitis. J Neurosci Res 1996;44:513-8.

22 Okada AA, Keino H, Fukai T, et al. Effect of type I interferon on experimental autoimmune uveoretinitis in rats. Ocul Immunol Inflamm 1998:6:215-26.

23 Teitelbaum D, Meshorer A, Hirshfeld T, et al. Suppression of experimental allergic encephalomyelitis by a synthetic polypeptide. Eur J Immunol $1971 ; 1: 242-8$.

24 Munari LM, Lovati R, Boiko A. Therapy with glatiramer acetate for multiple sclerosis (Cochrane Review). The Cochrane Library. 1 vol. Chichester: John Wiley, 2004

25 Munari LM, Filippini G. Lack of evidence for use of glatiramer acetate in multiple sclerosis. Lancet Neurol 2004;3:641.

\section{bmjupdates+}

bmjupdates+ is a unique and free alerting service, designed to keep you up to date with the medical literature that is truly important to your practice.

bmjupdates+ will alert you to important new research and will provide you with the best new evidence concerning important advances in health care, tailored to your medical interests and time demands.

Where does the information come from?

bmjupdates+ applies an expert critical appraisal filter to over 100 top medical journals A panel of over 2000 physicians find the few 'must read' studies for each area of clinical interest

Sign up to receive your tailored email alerts, searching access and more...

www.bmjupdates.com 